\title{
O QUE HÁ DE REAL E DE IRREAL COM O REALISMO: SEARLE VERSUS RORTY ${ }^{1}$
}

\author{
Paulo GHIRALDELLI JÚNIOR²
}

- RESUM 0: 0 texto fala a respeito do debate entre Searle e Rorty sobre "irracionalismo" de Rorty. Ele tenta mostrar que a posição de Rorty está fora do campo "realismo versus anti-realismo" e o "irracionalismo" não é um bom adjetivo. Searle estaria sobre uma linha incorreta em sua abordagem do tema da verdade em Rorty.

- PalaVRAS-CHAVE: Pragmatismo; racionalismo; pós-modernismo; Rorty; Searle; verdade.

Rorty vive dizendo que os filósofos deveriam conversar menos sobre a verdade e mais sobre a liberdade. No entanto, cada vez que ele diz isso, as objeções são tantas, são tantas as reclamações dos filósofos, que Rorty termina por escrever sempre mais um artigo sobre verdade! Talvez esta seja a sina do pragmatismo: uma vocação para conversar sobre filosofia política liberal sempre abortada pela necessidade de se voltar a temas, digamos, epistemológicos, talvez metafísicos. Quem sabe essa sina tenha tido um responsável, ou dois. Tudo pode ter começado quando William J ames definiu o pragmatismo como um método para a verdade. Aí passou um anjo torto que, tomando as coisas ao pé da letra disse amém e,

1 Palestra ministrada no Programa de Pós-Graduação em Ciências Cognitivas e Filosofia da M ente na UNESP - Marília - SP - Brasil.

2 Professor visitante da Auckland University, New Zealand. Departamento de Administração e Supervisão Escolar - FFC - UNESP - 17525-900 - Marília - SP - Brasil. 
então, condenou o projeto pragmático a se engalfinhar no debate sobre a verdade indefinidamente.

Alguns filósofos, ou mesmo alguns lógicos atuais, Susan Haack à frente, não acreditam nessa história de anjo torto. Para eles, o pragmatismo é mesmo uma filosofia da verdade. E não só: o pragmatismo, além de ser uma filosofia da verdade, desde seus fundadores, não estaria apartado do campo da teoria da verdade como correspondência e, por que não dizer, do realismo filosófico. Rorty, obviamente, não concorda com isso. É claro que ele, com uma erudição invejável em história da filosofia, sabe que Haack tem boas razões para falar o que fala sobre Peirce, James ou mesmo Dewey. Mas ele não entende a atividade filosófica como atividade fundacionista, e sim como atividade redescritiva, e por isso não se interessa em considerar as possíveis ligações dos velhos pragmatistas com o correspondentismo; segundo ele, isso não levaria a nada, digamos que isso apenas reforçaria o destino programado pelo meu anjo torto. Ele prefere ver James e Dewey ligados ao coerentismo, e essa é uma tese claramente defensável; e quer ver, também, James e Dewey ligados ao deflacionismo, e esta sim já me parece uma tese mais ousada, uma tese completamente inovadora, coisa que só um espírito inquieto como o de Rorty e, como ele mesmo diz, "do contra", poderia propor.

É esse espírito "do contra" que me faz ver em Rorty uma espécie de Nietzsche americano. É claro que ele mesmo não concorda com isso. Penso que ele jamais concordaria em colocar-se como discípulo de um filósofo europeu. Na sua leitura, é Nietzsche quem deve à America. Por Rorty, Nietzsche é um pragmatista europeu, e não ele, Rorty, ou mesmo Dewey, seriam Nietzsches americanos. Mas independentemente dessa história de ovo e galinha, gosto de chamar Rorty de um Nietzsche americano. E isso não para provocar o meu amigo J osé Carlos Bruni. Longe de mim querer alfinetar o Bruni. Gosto de ligar Rorty a Nietzsche para poder chegar a um ponto básico da história da filosofia, a meu ver um dos momentos mais importantes da história da filosofia, que é aquele em que Nietzsche escreveu o aforismo 16 de Além do bem e do mal. Pois é ali que Nietzsche fustiga Descartes e, afinal, toda a filosofia, colocando a pergunta: "Por que sempre a verdade?".

Considero essa pergunta de Nietzsche uma das mais importantes da história da filosofia ocidental. No contexto em que está posta, no aforismo 16, 0 alvo é Descartes. Mas não só. Ela é uma pergunta também, e talvez principalmente, contra Platão. E, sendo assim, ela é um dardo contra toda a Filosofia, a Filosofia com "F" maiúsculo. À primeira vista, parece uma pergunta cética. Mas ela não é uma pergunta cética. 0 cético, prin- 
cipalmente o cético de estilo cartesiano, ou seja, o cético epistemólogo profissional, quer colocar contra a parede aqueles que acreditam na possibilidade da verdade. Nietzsche, diferentemente, quer revolver os cérebros e os intestinos dos filósofos fazendo uma pergunta de sabor psicológico, talvez sociológico e antropológico: "Por que sempre a verdade?". Por que sempre a verdade?

0 que Nietzsche faz, portanto, é perguntar pelo imperguntável: por que a tarefa de busca da verdade é a tarefa de busca da verdade? Por que há esta tarefa? Haveria outra coisa para fazer em filosofia senão sair da caverna de sombras em direção à iluminação da paidéia? Não é justamente a tarefa própria e única da filosofia nos tirar da caverna e nos colocar em contato com a verdade? E isso não é o que há de mais óbvio para fazer? Ora, N ietzsche pergunta por que é que inventamos tudo isso! Perguntar sobre o imperguntável e, mais que isso, conversar sobre 0 inconversável, tocar em tabus, eis aí o ponto de encontro entre Nietzsche e Rorty. É claro que Rorty não está deslumbrado com Nietzsche. Ele sabe muito bem, como já falou várias vezes, que rimos quando lemos Nietzsche, mas que só rimos gostoso mesmo quando voltamos a ele depois de alguns anos e rimos de tudo, inclusive e principalmente do próprio Nietzsche. $\mathrm{E}$ isso, entre outros motivos, pelo fato de que Nietzsche queria muito ser ouvido, mas tinha lá suas dúvidas se seria mesmo ouvido, dado que tinha de escrever com um vocabulário novo, talvez ininteligível aos filósofos. Mas Rorty, tendo podido rir de tudo isso, escreve prosaicamente dentro da filosofia. A pesar de toda a sua busca pelo novo, pela criação que só a poesia pode promover, Rorty continua filósofo, continua conversando nos termos do vocabulário da filosofia. A opção pragmático-deflacionista é, assim, a maneira de Rorty de fazer duas coisas: primeiro, conversar sobre a verdade, respeitando os limites do vocabulário técnico da filosofia contemporânea na tradição analítico-pragmática; segundo, manter viva a chama espiritual da pergunta nietzschiana "por que sempre a verdade?". Essa estratégia de Rorty não é só original, ela é antes de tudo engraçada, porque de certo modo ela afligiria o próprio Nietzsche, ela revolveria os intestinos e o cérebro daquele que mais quis revolver intestinos e cérebros filosóficos! Ao mesmo tempo essa estratégia é, a meu ver, uma das melhores maneiras de manter viva a filosofia de Nietzsche, dentro do campo filosófico, no fim do século XX.

A conversa pragmático-deflacionista de Rorty pode ser exposta em duas partes. Primeiro, há o seu ataque à teoria correspondentista da verdade. Segundo, sua opção por uma narrativa sobre a verdade que 
privilegia a semântica em detrimento da epistemologia. Neste último caso, ele visa mais se desfazer de todo e qualquer debate entre realismo versus anti-realismo que de tomar partido pelo anti-realismo. Este segundo passo alia-se ao seu anti-representacionalismo, e é isto tudo que eu venho chamando de postura pragmático-deflacionista.

Pois bem, o que vou fazer daqui até o fim desta exposição é tentar mostrar, da maneira mais breve e clara possível, quiçá didática, um dos pontos polêmicos referentes à primeira parte da conversa pragmáticodeflacionista de Rorty.

Os pontos polêmicos do trajeto de Rorty se tornam mais claros quando abordados a partir de suas respostas a seus críticos. Quanto aos aspectos técnicos do seu discurso filosófico, há, entre seus críticos, quatro filósofos que não podem deixar de serem lidos: Searle, Putnam, Taylor e Habermas. Escolho aqui, hoje, a polêmica com Searle (1992), em um de seus aspectos, que é a crítica de Searle ao que ele chama de "irracionalismo de Rorty" ou, mais amplamente, o que ele chama de "nietzschianismo" de Rorty, Kuhn, Derrida e Foucault. Não escolho essa crítica à toa. Ela me servirá para expor exatamente o ponto polêmico da posição de Rorty em um dos aspectos de seu ataque à teoria da verdade como correspondência, ou, em outras palavras, seu ataque ao realismo.

A crítica de Searle ao que ele chama de irracionalismo-nietzschismo de Rorty possui derivações interessantes para a filosofia da educação, dado que ela é, antes de tudo, uma crítica ao que seria a postura atual dos intelectuais na condução do trabalho de ensino e pesquisa nas universidades americanas hoje. Em suma, já é até matéria jornalística o fato de que Searle vê em Rorty e outros a postura relativista que estaria deteriorando a "tradição racionalista ocidental" e, conseqüentemente, 0 ambiente acadêmico americano. Eu, que passei a maior parte dos últimos vinte e dois anos trabalhando com filosofia da educação, me interesso bastante por esse tema. Acho um tema de suma importância para a filosofia da educação o debate sobre o relativismo, como ele está posto nos Estados Unidos desde o final dos anos 80 ou, ainda, desde a publicação de A condição pós-moderna por Lyotard no final dos anos 70. Mas não é por esse caminho que vou conduzir as coisas hoje. Como já disse, vou me restringir aos detalhes técnicos da crítica de Searle e, dentre esses detalhes, vou apontar para a sua crítica à crítica de Rorty à noção correspondentista de verdade e ao real ismo.

Searle, em uma só frase, procura apanhar os dois lados do que seria a visão de Rorty sobre a verdade. Searle diz: Rorty fala "repetidamente que 'verdadeiro' é apenas um termo de recomendação que usamos para 
elogiar aquelas crenças que pensamos como boas de se acreditar, e que a verdade é fabricada e não descoberta". Searle (1992) diverge de ambas as afirmações. Ele não acha válido a redefinição de verdade "como o que é bom de se acreditar". E também não acha que "a verdade é feita e não descoberta". Segundo Searle, a afirmação de Rorty ou é circular ou é obviamente falsa. Ou seja, se, como Rorty faz, redefinimos "verdade", tomando-a como o que é bom de se acreditar, acabaremos depois por procurar um critério para bom de se acreditar e encontramos que tal critério pode ser definido como verdade ou como correspondência à realidade. Isso nos levaria junto com Rorty para o fundo do poço da circularidade. Se, por outro lado, não redefinimos "verdade", então temos de ficar com o fato de que há muitas proposições que por várias razões são boas para se acreditar mas que não são verdadeiras, e há muitas proposições que também por várias razões são péssimas de se acreditar mas que são verdadeiras. Isso nos levaria junto com Rorty para um outro poço, o da simples falsidade.

Bem, tudo isso Searle diz em relação ao termo "verdadeiro" como termo de elogio. Agora, vamos à idéia que Searle atribui a Rorty de que a verdade não é descoberta mas fabricada.

Segundo Searle, essa afirmação de Rorty é protegida pela ambigüidade. Uma vez que a verdade aparece sempre em declarações, e que as declarações são feitas pelas pessoas, então a verdade é realmente produzida e não descoberta. Todavia, diz Searle, disso não se segue o fato de que não há nenhuma realidade existindo independentemente daquelas declarações que estariam em correspondência com tal realidade. Há um sentido, diz Searle, no qual se pode dizer que a verdade é produzida e não descoberta, que é quanto ao fato das declarações lingüísticas serem feitas, produzidas. Mas haveria um sentido, consistente com este, no qual a verdade é descoberta. "O que se descobre", diz ele, "é o que é que torna as declarações verdadeiras" ou falsas. E Searle resume: "As declarações verdadeiras são feitas, mas a verdade das declarações não é feita, é descoberta". Assim, na conta de Searle, se tiramos a ambigüidade das afirmações de Rorty, então tudo cai por terra.

E então, o que resta a Rorty dizer? Seriam mesmo as posições de Rorty este castelo de cartas que a crítica de Searle faz parecer? Varreríamos Rorty para fora do cenário filosófico, acusando-o de ilogicidade da mesma maneira que alguns pensaram poder varrer $\mathrm{N}$ ietzsche quando ele paradoxalmente disse que "não há fatos, só interpretações"? Não creio.

Todavia, antes de prosseguir, quero notar duas imprecisões na crítica de Searle. Primeiro, que Rorty não diz apenas que a verdade é o que 
é bom de se acreditar, ele diz também outras coisas. Ele enumera outros usos básicos do termo verdadeiro. Mesmo que ficássemos só com a idéia de que a verdade é o que é bom de se acreditar, isto é, se apenas ficássemos na parte em que Rorty diz que o termo "verdadeiro" é um termo de elogio, teríamos de notar que ele não vê necessidade de voltar e procurar critérios para o elogio na correspondência. Isso seria procurar de novo caminhar pela epistemologia quando já se optou pela semântica e por uma semântica deflacionista. Por isso, a idéia da circularidade, a meu ver, não cabe. Pelo menos não cabe assim, tão diretamente como Searle, a coloca. Segundo, Rorty não diz que a verdade é feita e não é descoberta, o que ele diz, sim, é que temos de abandonar essa dualidade fabricar/descobrir.

Bem, eis aí algumas coisas que, talvez, pudéssemos objetar a Searle. Mas eu não quero ir por aí. Não quero invalidar a crítica de Searle, pegando aqui e acolá pontos nos quais ele não teria sido fiel ao texto rortyano. Isso seria tarefa de exegetas e, creio, pareceria muito com o que os marxistas faziam no passado quando liam uma crítica contra Marx; eles procuravam aqui e ali onde o crítico teria "atravessado" o texto. Não, não vou repetir esse procedimento que nunca levou a nada a não ser à formação de igrejinhas. A crítica de Searle permite uma boa conversa, pois ela toca um ponto central de todo o debate realismo versus anti-realismo, e lembra em parte 0 debate entre Putnam e Rorty, entre Taylor e Rorty, entre Susan Haack e Rorty.

A tentemos para o que Searle está dizendo. Ele está falando que em um certo sentido a verdade é descoberta e não fabricada. Uma declaração verdadeira é fabricada na medida em que depende do falante, mas a verdade da declaração verdadeira independe do falante, ela tem a ver com um algo que é independente do falante e, então, independente da própria declaração lingüística. Assim, se a declaração é sobre montanhas, este "algo" tem a ver com as montanhas como existentes antes de toda e qualquer declaração, este "algo" tem a ver com a "existência da realidade independente" das declarações lingüísticas. É isso mesmo que Searle está pensando, pois ele define o "realismo", ao qual ele se filia, como a posição que sustentaria a "tradição racionalista ocidental" e que advoga que "a realidade existe independentemente das representações humanas". E ele explica bem o que quer dizer com isso. Ele diz: trata-se da idéia de que "embora tenhamos representações mentais e lingüísticas do mundo na forma de crenças, experiências, declarações e teorias, há um mundo 'lá fora' que é totalmente independente dessas representações". E ele continua: "isto tem a conseqüência, por exemplo, de que 
quando nós morrermos, como morreremos, o mundo continuará em grande parte não afetado pelo nosso falecimento".

Se é assim, então estaria Rorty, que na conta de Searle acha que a verdade não é descoberta mas fabricada, negando que possamos admitir que as montanhas existem antes de nós falarmos delas?

Se Searle está mesmo pensando assim, e tudo indica que está, Rorty foi mais ou menos transformado por ele em algo equivalente a um personagem de um chiste contado por Gramsci. Se me lembro bem, Gramsci falou de um leitor do idealismo kantiano que, tendo ficado sabendo da existência do fenômeno e da realidade em si, olhava rapidamente e de relance por trás dos ombros para ver a realidade fenomênica se formando!

Pelo que Rorty responde a Searle, ele teve a mesma impressão que eu. Pelo que Searle escreve, parece que os filósofos que não acreditam na realidade independente da mente, como é o caso de Rorty, devem então "negar que havia montanhas antes das pessoas terem tido a idéia de 'montanha' em suas mentes ou a palavra 'montanha' em suas linguagens". Todavia, lembra Rorty, ninguém nega isso; "ninguém pensa que há uma cadeia de causas que torna as montanhas um efeito de pensamentos ou palavras". Pessoas como Kuhn, Derrida e Rorty, segundo o próprio Rorty, "acreditam que é sem sentido perguntar se realmente há montanhas ou se é meramente conveniente para nós falarmos sobre montanhas". "Nós também pensamos", diz Rorty, "que é sem sentido perguntar, por exemplo, se neutrinos são entidades reais ou meramente ficções heurísticas úteis". E ele continua: é isso que pretendemos quando insistimos

que é sem sentido perguntar se a realidade é independente do nossos modos de falar sobre ela. Dado que há condições para se falar de montanhas, como certamente há, uma das verdades óbvias sobre montanhas é que elas estavam aqui antes de falarmos delas. Se você não acredita nisto, provavelmente você não sabe como jogar os jogos de linguagens habituais que empregam a palavra "montanha". Porém, a utilidade desses jogos de linguagem não tem nada a fazer com a questão de se a realidade em si mesma, à parte do modo que é conveniente para os seres humanos descrevê-la, possui montanhas. (Rorty, 1998, p.85-7)

Assim, para Rorty, o problema todo entre ele e Searle está na maneira como usamos a palavra "independente". Falamos em independência representacional e em independência causal, mas para Rorty só o segundo tem sentido. Os jogos de linguagem que jogamos habitualmente comportam o segundo modo de falar de independência, mas falar do primeiro modo levaria a situações pouco confortáveis e a impasses filosóficos tal- 
vez desnecessários e mesmo sem sentido. 0 raciocínio de Rorty é, grosso modo, o seguinte. Nos nossos jogos de linguagem habituais, uma montanha é causalmente independente de boa parte das declarações lingüísticas sobre ela, mas que sentido teria em falar, mantendo-se nos jogos de linguagem que conhecemos, que a montanha é representacionalmente independente? Estaríamos falando da montanha-para-alémde-todas-as-descrições? Mas dentro de nossos jogos de linguagem, 0 que significa falar em montanha para além de tudo que a palavra "montanha" implica? Falamos de montanhas, e quando falamos delas admitimos que uma de suas características é ser causalmente independente das declarações que fazemos, mas segundo Rorty não podemos dizer que elas são representacionalmente independentes nem que não são representacionalmente independentes, pois nem caberia tal pergunta. Nossos jogos de linguagem habituais entram em colapso quando queremos falar da maneira dual que a epistemologia realista quer nos obrigar a falar, isto é, quanto temos de falar da realidade-em-si e da realidadepara-nós, pois isso significaria ter de falar sobre a realidade para além das relações descritivas que temos com ela. Teríamos de dizer que encontramos um modo de falar de fatos sem interpretá-los.

0 pragmatismo, como Rorty o entende e o pratica, é uma perspectiva holística, contextualista. Nessa perspectiva, uma coisa $X$ qualquer é 0 que se pode falar dela em suas relações. Para além de suas relações, 0 que seria um $X$ ? Um $X$ não é algo com duas camadas, uma formada pelas suas relações e outra prenhe de características não-relacionais. Isto é, para o pragmatismo de Rorty não vale a equação $X=$ "características meramente relacionais" + "características intrínsecas". Isso não tem sentido para o holismo da postura pragmatista rortiana.

As coisas ficam mais claras quando Rorty debate com Charles Taylor, sobre o mesmo ponto em que responde a Searle. Rorty dá o exemplo dos dinossauros. Cito Rorty (1998, p.85-7):

Considere os dinossauros. Uma vez que você descreve alguma coisa como um dinossauro, sua cor de pele e sua vida sexual são causalmente independentes de sua descrição dele. M as antes de você descrevê-lo como um dinossauro, ou como alguma outra coisa, não havia nenhum sentido na afirmação de que ele está "lá fora" tendo propriedades. 0 que está lá fora? A coisa-em-si? 0 mundo? Conte-nos mais. Descreva-o em mais detalhes. Uma vez que você assim faz, mas somente então, estamos em uma posição de falar quais das suas propriedades são causalmente independentes de terem sido descritas e quais não. Se você o descreve como um dinossauro, então podemos falar que a característica de ser ovíparo é causalmente independente de nossa descrição dele, mas a caracterís- 
tica de ser um animal cuja existência tem sido conjecturada só nos séculos mais recentes não é. Isso não é uma distinção entre as características "intrínsecas" e as características "meramente relacionais" dos dinossauros. É apenas a distinção entre as relações-causais-com-algumas-coisas-(ovos)-sob-uma-descrição e as relações-causais-com-outras-coisas-(nós)-sob-uma-descrição.

Quando o realista ouve essa fala de Rorty, ele acredita poder objetar. A objeção realista que se pode fazer a Rorty aqui é a que segue. Há relações causais que se alteram sob redescrição, como a relação causal dos dinossauros conosco, e há relações causais que não se alteram sob redescrição, como a relação dos dinossauros com seus ovos. 0 realista, diante disso, pode dizer: as descrições que descrevem relações causais que não se alteram sob redescrição são assim ou (1) porque a realidade e a verdade são invariantes ou (2) porque a unidade é uma característica desejável da ciência. Essa dupla opção realista estaria, em qualquer caso, ou atrelada à idéia de que as relações causais são mais "intrínsecas" às coisas que as descrições dessas coisas, ou atrelada à idéia de que descrições de coisas como causalmente relacionadas são descrições mais próximas do modo que as coisas são de "qualquer modo" do que como descritas por outros modos.

Todavia, Rorty insiste, deveríamos apenas ficar com a conclusão de que há relações causais que devem permanecer constantes, e nada mais. Conversar como o realista conversa nos levaria de volta a impassses, como por exemplo a idéia de termos de falar do algo que está para além de toda descrição. 0 que é "algo" para além de toda descrição?

Sendo assim, não há cabimento para Rorty termos de aceitar o realismo quando este diz que a verdade de qualquer afirmação depende "de como o mundo é". Caso a expressão "de como o mundo é" inclua só relações causais, como quer o realismo, então Rorty não pensa em dizer que a verdade depende de como o mundo é. Todavia, se a expressão "de como o mundo é" engloba relações causais mais descrições das relações, como pretende o pragmatismo, então certamente ele concorda que a verdade depende de como o mundo é. Rorty quer escapar da idéia de colocar a verdade sobre o crivo da dualidade fabricar/descobrir. Mas entre descobrir e fabricar, é certo que para ele a verdade não pode ser descoberta. Isso seria admitir que a verdade depende "de como o mundo é" no primeiro sentido dessa expressão, isto é, no sentido no qual tal expressão engloba apenas relações causais sem englobar também as descrições pelas quais nós podemos conversar sobre tudo, inclusive falar de relações causais e descrevê-las. 
Volto agora à primeira objeção de Searle a Rorty, a que ele não concorda com a redefinição que Rorty faz do termo "verdadeiro", tratando- o como um termo de elogio. Searle diz que, se tratamos a verdade como o que é bom de se acreditar, mais cedo ou mais tarde procuraremos um critério para "bom de se acreditar" e certamente encontraremos na verdade e na correspondência esse critério, e então cairíamos em um círculo. Como já disse, entendo que Searle assim pensa porque ele não consegue imaginar a verdade sendo tratada fora dos cânones epistemológicos, simplesmente pela semântica. Rorty é deflacionista exatamente porque, advogando que o fundacionalismo metafísico e/ou epistemológico chegou a um impasse, optou por tratar a verdade em termos semânticos. Nesses quadros, o que importa para Rorty não é falar da verdade, mas sim enumerar os usos do termos "verdadeiro". Tratar desses usos implicaria uma outra fala, pois nos levaria ao debate de Rorty não só com Susan Haack e Putnam, mas principalmente com Habermas, e não há espaço para tal. Sou obrigado então a encerrar por aqui. Ou seja, volto a Nietzsche.

Comecei dizendo que a plataforma pragmático-deflacionista de Rorty, na qual se incluem suas críticas ao anti-realismo aqui expostas, é uma maneira de manter viva a pergunta de Nietzsche: "Por que sempre a verdade?". Agora gostaria de corrigir um pouco isso, para ser justo com Rorty e com Nietzsche. É que Rorty é completamente antifundacionalista e quer levar às últimas conseqüências o deflacionismo que existe na pergunta "por que sempre a verdade?". Não creio que era este exatamente 0 intuito de N ietzsche. Como o próprio Rorty lembra, a leitura que Heidegger faz de Nietzsche tende a mostrar que este não se libertou completamente da busca de fundamentos metafísicos. Creio que devemos considerar isso. Quem lê o aforismo 22 de Além de bem e mal não fica só surpreso com o início do texto, que joga todo esforço teórico em um impasse, e talvez toda a filosofia, mas fica mais surpreso ainda quando no final aparece a vontade de potência fazendo um papel dúbio, talvez fundacionalista. Temos de considerar que a noção de vontade de potência em Nietzsche, para muitos intérpretes, fica entre uma postura cosmológica e uma postura metafísica. E se é assim, a pergunta "por que sempre a verdade?", a meu ver, não teria toda a radicalidade que eu quis conferir a ela no início. Acho que valeria a pena confiar mais no riso de Rorty, o riso de tudo, não só do realismo de Searle mas também da pergunta de Nietzsche e, quem sabe, de si próprio, que, no limite, não pode conversar sobre a liberdade como gostaria, tendo de ficar conversando sobre a verdade. 
GHIRALDELLI JÚNIOR, P. What there is of real and unreal in Realism: Searle versus Rorty. Trans/Form/A ção (São Paulo), v.21-22, p.119-129, 1998-1999.

- ABSTRACT: The article talks about debate between Searle and Rorty on a "irrationalism" of Rorty. The text tries to show that the Rorty's position is out of the field "Realism versus Anti Realism" and the "irracionalism" is not a good adjective. Searle would be on a incorrect line in his account of the Rorty's theme of truth.

- KEYWORDS: Pragmatism; Rationalism; Postmodernism; Rorty; Searle; truth.

\section{Referências bibliográficas}

SEARLE, J. Rationality and realism: what is at stake? Daedelus, v.122, n.4, p.5584, 1992.

RORTY, R. Truth and Progress: Philosophical Papers. Cambridge: Cambridge University Press, 1998. v.III 